\title{
ESTUDO DA SUBSTITUIÇÃO TOTAL DA MAGNÉSIA POR RESÍDUOS REFRATÁRIOS MgO-C EM REFRATÁRIOS CONFORMADOS DA MESMA CLASSE*
}

\author{
Diógenes Albert Gomes \\ Diêgo Ribeiro Fraga ${ }^{2}$ \\ Paulo Henrique Mesquita ${ }^{3}$ \\ João Bosco dos Santos ${ }^{4}$ \\ Leonardo Neves ${ }^{5}$ \\ Ricardo Luiz Perez Teixeira ${ }^{6}$ \\ Gilberto Fernandes Lima ${ }^{7}$
}

\section{Resumo}

Neste trabalho são apresentados os impactos físicos e mecânicos da reciclagem de insumos refratários compostos por óxidos de magnésio ligado ao carbono, visando à reutilização destes como matéria prima para a confecção de novos tijolos. Os resíduos refratários substituíram, na formulação proposta, 100\% massa de $\mathrm{MgO}$ utilizado nestes tijolos. O estudo envolveu a confecção dos novos tijolos e a realização de ensaios de caracterização dos tijolos produzidos, através de ensaios físicos. Os resultados mostraram uma porosidade final elevada na condição sem cura, resultando em valores de densidade e resistência inferiores aos dos tijolos produzidos com matérias-primas virgens.

Palavras-chave: Refratários; Reciclagem; Sustentabilidade.

\section{STUDY OF MgO-C SPENT REFRACTORY WASTE RECYCLING FROM MgO FOR METALLURGICAL APPLICATIONS}

\section{Abstract}

This paper presents the physical and mechanical impacts of recycling refractory inputs composed of magnesium oxides bonded to carbon, in order to reuse these as raw material for the production of new bricks. Refractory residues replaced in the proposed formulation, $100 \%$ mass of $\mathrm{MgO}$ used in these bricks. The study involved the making of the new bricks and carrying out characterization of bricks produced trials using physical tests. The results showed high porosity in a final condition without curing, resulting in lower bulk density and resistance of the bricks produced from virgin raw materials.

Keywords: Refractories; Recycling; Sustainability.

1 Graduando em Engenharia Metalúrgica, Universidade do Estado de Minas Gerais (UEMG), João Monlevade, MG, Brasil.diogenesag@bol.com.br

2 Eng. Metalurgista, UEMG, João Monlevade, MG, Brasil. diegorfraga@yahoo.com.br

3 Eng. Metalurgista, UEMG, João Monlevade, MG, Brasil.

paulohm_@hotmail.com

4 Eng. Metalurgista, Professor, Pesquisador, M.Sc.. em Engenharia Metalúrgica e de Materiais, Centro Federal de Educação Tecnológica, Departamento de Engenharia de Materiais, Belo Horizonte, MG, Brasil. joaobosco@des.cefetmg.br

5 Eng. Metalurgista, Professor, Pesquisador, Dr. em Engenharia Metalúrgica e de Materiais, Centro Federal de Educação Tecnológica, Departamento de Engenharia de Materiais, Belo Horizonte, MG,Brasil.prof.leonardoneves@gmail.com

6 Eng. Químico, Dr. Em Ciências, Engenharia Metalúrgica e de Materiais pela UFRJ, professor de materiais metálicos, Dr. em Engenharia Metalúrgica e de Materiais, Universidade Federal de Itajubá- Itabira, Curso de Engenharia de Materiais, Itabira, Brasil, Ricardo.luiz@unifei.edu.br.

7 Eng. Metalurgista, Professor, Pesquisador, M.Sc. em Engenharia Metalúrgica e de Materiais, Universidade do Estado de Minas Gerais (UEMG), João Monlevade e Pontifícia Universidade Católica de Minas Gerais (PUC Minas), Belo Horizonte, MG, Brasil. amilleste@uol.com.br. 


\section{INTRODUÇÃO}

Devido à evolução do conceito de sustentabilidade, a visão do descarte de resíduos torna-se não somente ambientalmente impactante, mas as questões econômicas também são afetadas. Visto isso, a reutilização e a reciclagem dos resíduos nos processos tornam a atividade vantajosa para todas as dimensões do negócio e da sociedade, quando eficaz.

Como contribuição à pesquisa de reciclagem dos resíduos refratários, este trabalho propõe estudar a viabilidade da reciclagem dos resíduos refratários compostos de Óxido de Magnésio ligados ao carbono, gerados na indústria siderúrgica e promover a redução de impactos ambientais negativos.

\subsection{Revisão da Literatura}

Os refratários podem ser obtidos pelo uso majoritário de determinado composto ou pela conjugação de vários deles, garantindo uma gama ampla de materiais com propriedades adequadas a diferentes aplicações [7].

A classificação dos produtos refratários pode seguir diferentes critérios, como modo de aplicação, densidade, principal fase termodinâmica, sistema ligante, sistema de aplicação, composição química ou basicidade (relação entre a \% em massa de $\mathrm{CaO}$ presente pela \% em massa de $\mathrm{SiO}_{2}, \% \mathrm{CaO} / \% \mathrm{SiO}_{2}$ ) [8].

À medida que os produtos refratários encerram seu ciclo de vida, a geração de resíduos provenientes destes materiais é inevitável [1-5]. De acordo com os dados fornecidos pela Magnesita (2011), estima-se que somente o setor siderúrgico brasileiro gere em média 50.000 toneladas de resíduos refratários por ano, sendo que nem sempre, por dificuldades logísticas, corporativas ou técnicas, o destino final dos resíduos é ambientalmente correto, além de ser, muitas vezes, incógnito [6].

\subsection{Refratários MgO-C}

Pela definição do Handbook of Refractory Practice [8], os refratários de magnésiacarbono (MgO-C) são compósitos a base de magnésia sinterizada ou fundida ( $\mathrm{MgO}$ ), uma fonte de carbono, comumente a grafita por ter alta estabilidade química, e um ligante de preferência com alta concentração de carbono fixo, podendo ser a resina fenólica do tipo resol, que apresenta propriedades superiores em termos de resistência à laminação, ou a resina novolaca, que é um polímero termofixo, apresenta como vantagem a capacidade de mistura e processamento a frio dos materiais refratários que as contem, reduzindo custos operacionais e com equipamentos [9]. A figura 1 traz a disposição esquemática dos componentes contidos neste tipo de refratário:

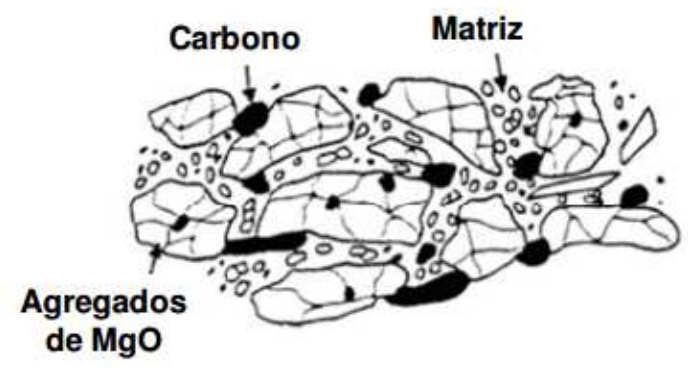

Figura 1 - llustração esquemática da estrutura dos refratários MgO-C [9]. 
Segundo Schacht [10] devido a suas características de elevada resistência ao choque térmico e resistência a penetração da escória, os tijolos de MgO-C são utilizados amplamente na indústria siderúrgica, destacando-se especialmente em fornos básicos a oxigênio, panelas de aço e fornos elétricos a arco.

De acordo com Carniglia [7] a erosão ou desgaste nos tijolos de MgO-C depende do tipo de forno e de suas condições operacionais. O carbono contido nos tijolos de $\mathrm{MgO}-\mathrm{C}$ inibe a penetração da escória criando um bloqueio físico dos poros e reduzindo a molhabilidade, porém ele pode ser oxidado, elevando as taxas de desgaste do revestimento refratário.

Nos fornos básicos a oxigênio, um dos fatores de maior importância a serem considerados é a formação da magnésia em camadas densas na estrutura refratária (face quente). Esta proteção, por meio da redução da porosidade, contribuí para o aumento resistência química e, consequentemente, maior durabilidade dos tijolos $\mathrm{MgO}-\mathrm{C}$.

\subsection{Reciclagem de Materiais Refratários}

Apesar da compreensão da necessidade e dos benefícios da reciclagem de refratários serem evidentes, muitos desafios dificultam a sua execução. $O$ primeiro está relacionado à grande variedade de resíduos refratários existentes, muitos deles contendo contaminantes oriundos do processo (escória, sais, e outros.) e de alterações provocadas pelo processo (metais reagindo formando carbetos ou nitretos, dentre outros), o que exige uma rota específica para o tratamento de cada um desses materiais. O segundo problema está relacionado à logística do projeto de reciclagem, que envolve custos de frete e manuseio dos resíduos gerados no cliente além do gerenciamento dos inservíveis oriundos do processo de reciclagem em si [11].

\section{MATERIAIS E MÉTODOS}

O estudo experimental envolveu o processamento e a análise química dos tijolos MgO-C usados, a seleção e dosagem dos materiais componentes do novo tijolo, a confecção da massa para compactação, a conformação da massa refratária por prensagem e a realização dos ensaios padrão previstos em norma.

As amostras utilizadas provieram de um Conversor LD. A figura 2 ilustra, em síntese, as etapas envolvidas na metodologia desta pesquisa.

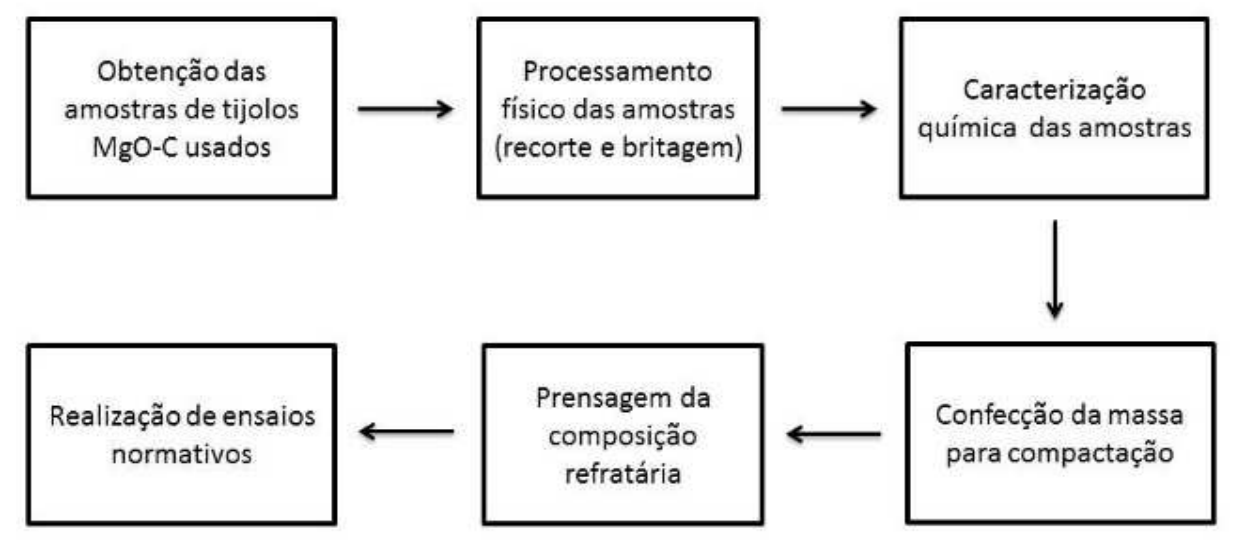

Figura 2 - Etapas do método de pesquisa. 
As amostras como coletadas foram inicialmente recortadas para remoção da face quente dos tijolos, isto é, a área mais externa que sofreu contaminação por metais e escória durante o tempo em serviço. A margem de corte foi definida como distante $1,5 \mathrm{~cm}$ das arestas. A face quente, como o nome sugere, é a região do tijolo que foi submetida às condições máximas de temperatura em serviço [12-14].

Após a conclusão da etapa de recorte, procedeu-se a britagem dos tijolos em três faixas, de $0 \mathrm{~mm}$ a $4 \mathrm{~mm}$, cuja as massas obtidas estão apresentadas na Tabela 1 , escolhidas com referência à distribuição granulométrica típica da magnésia que garante boas propriedades físicas e termomecânicas aos refratários MgO-C, de acordo com Joardar [15].

Tabela 1 - Rendimento da britagem dos tijolos MgO-C.

\begin{tabular}{cc}
\hline Faixa granulométrica & Massa $(\mathrm{Kg})$ \\
\hline $4,00 \mathrm{~mm}-2,00 \mathrm{~mm}$ & 10,072 \\
$2,00 \mathrm{~mm}-1,00 \mathrm{~mm}$ & 9,682 \\
$1,00 \mathrm{~mm}-0 \mathrm{~mm}$ & 9,900 \\
TOTAL & 29,654 \\
\hline
\end{tabular}

\subsection{Análise Química das Amostras}

A composição característica dos tijolos em estudo foi determinada por Fluorescência de Raios X (FRX), técnica de análise elementar. Esta técnica baseia-se na mensuração das intensidades dos raios $X$ emitidos pelos elementos componentes da amostra quando excitados por raios $X$ liberados por tubos de raios $X$, raios gama ou ainda raios $X$ oriundos de uma fonte radioativa com energia adequada [16].

$\mathrm{Na}$ tabela 2 apresenta a análise química das amostras obtidas por Fluorescência de raios $\mathrm{X}$.

Tabela 2 - Resultado da análise química por fluorescência de raios X.

\begin{tabular}{cc}
\hline $\begin{array}{c}\text { Espécie } \\
\text { química }\end{array}$ & $\% \mathrm{~m} / \mathrm{m}$ \\
\hline $\mathrm{C}$ & 15,58 \\
$\mathrm{SiC}$ & 0,05 \\
$\mathrm{SiO} 2$ & 0,87 \\
$\mathrm{TiO} 2$ & 0,03 \\
$\mathrm{Al} 2 \mathrm{O} 3$ & 5,29 \\
$\mathrm{Cr} 2 \mathrm{O} 3$ & 0,00 \\
$\mathrm{Fe} 2 \mathrm{O} 3$ & 0,49 \\
$\mathrm{MnO}$ & 0,07 \\
$\mathrm{CaO}$ & 0,82 \\
$\mathrm{MgO}$ & 92,12 \\
$\mathrm{Na} 2 \mathrm{O}$ & 0,2 \\
$\mathrm{~K} 2 \mathrm{O}$ & 0,00 \\
$\mathrm{P} 2 \mathrm{O} 5$ & 0,06 \\
$\mathrm{ZrO} 2$ & 0,00 \\
\hline
\end{tabular}

Evidencia-se o alto teor de carbono característico dessa classe refratária. Deve-se observar que o teor de carbono é dado em relação à massa total da amostra e o teor das demais espécies em relação à massa da amostra subtraída da massa de carbono. 


\subsection{Produção dos Novos Tijolos MgO-C}

O processo de elaboração dos tijolos contendo majoritariamente os resíduos refratários, processados segundo descrito anteriormente, teve início com a determinação da composição visada para o produto. Buscou-se dentre os produtos catalogados de empresas produtoras do tijolo original, um tijolo cuja composição padrão mais se aproximasse da análise química apresentada, observando-se principalmente o teor de $\mathrm{MgO}$, carbono e o tipo de ligante utilizado.

A tabela 3 traz a composição adotada como referência neste trabalho.

Tabela 3 - Composição referência para os tijolos MgO-C [7].

\begin{tabular}{cc}
\hline $\begin{array}{c}\text { Espécie } \\
\text { química }\end{array}$ & $\% \mathrm{~m} / \mathrm{m}$ \\
\hline $\mathrm{C}$ & 14,00 \\
$\mathrm{MgO}$ & 91,20 \\
$\mathrm{Al} 2 \mathrm{O} 3$ & 6,20 \\
$\mathrm{Fe} 2 \mathrm{O} 3$ & 0,60 \\
$\mathrm{CaO}$ & 1,00 \\
$\mathrm{SiO} 2$ & 0,80 \\
\hline
\end{tabular}

A partir da referência citada, foram determinadas as proporções de cada componente dos tijolos, obtendo-se os valores apontados na tabela 4.

Tabela 4 - Distribuição dos materiais componentes dos novos tijolos.

\begin{tabular}{cc}
\hline Composição & $\% \mathrm{~m} / \mathrm{m}$ \\
\hline Resíduo refratário $4 \mathrm{~mm}-2 \mathrm{~mm}$ & 20,00 \\
Resíduo refratário $2 \mathrm{~mm}-1 \mathrm{~mm}$ & 30,00 \\
Resíduo refratário $1 \mathrm{~mm}-0 \mathrm{~mm}$ & 45,00 \\
Grafita 95100 & 3,00 \\
Alumínio em pó & 2,00 \\
\hline
\end{tabular}

Na composição apresentada utilizou-se alumínio em pó com a função desoxidante em teor típico para os tijolos da classe e, a fim de se adequar o teor de carbono da mistura final, adicionou-se grafita 95100. A quantidade de grafita adicionada foi definida considerando-se que aproximadamente $25 \%$ do carbono original encontrase blindado por outras fases ao fim da campanha do refratário. $O$ cálculo do teor de grafita adicionado foi feito pela equação 1 .

$$
\% \text { Graf }=14-(\% \text { Res })(\% \text { C })(0,75)
$$

Em que temos:

\%Graf - Porcentagem de Grafita adicionada

$\%$ Res - Porcentagem de resíduos refratários

$\% \boldsymbol{C}$ - Porcentagem de carbono presente nos resíduos

A distribuição granulométrica do resíduo apresentada na tabela 4, baseou-se nos valores geralmente empregados para a magnésia eletrofundida e nas faixas indicadas por Joardar [15]. Segundo o autor, a granulometria ótima da mistura tem relação com o teor de carbono dos refratários MgO-C, como mostrado na tabela 5. 
Tabela 5 - Distribuição granulométrica em função do teor de grafita

\begin{tabular}{ccc} 
Granulometria & Grafita $<12,5 \%$ & Grafita $>12,5 \%$ \\
\hline $4,00 \mathrm{~mm}-2,00 \mathrm{~mm}$ & $20-25 \%$ & $25-30 \%$ \\
$2,00 \mathrm{~mm}-0,50 \mathrm{~mm}$ & $35-40 \%$ & $33-38 \%$ \\
$0,50 \mathrm{~mm}-0,20 \mathrm{~mm}$ & $10-15 \%$ & $12-17 \%$ \\
$<0,20 \mathrm{~mm}$ & $25-30 \%$ & $20-25 \%$ \\
\hline \multicolumn{2}{c}{ Fonte: Adaptado de (Joardar, 2009) [15]. }
\end{tabular}

O agente de ligação adotado foi a resina fenólica tipo novolaca, inicialmente a 2,5\% em relação à massa refratária seca. Nos testes laboratoriais este valor inicial pode ser alterado caso não se verifique, ao longo do processo de mistura, uma consistência adequada à prensagem.

O processo de mistura foi concluído em aproximadamente 20 minutos, quando foram verificadas condições aceitáveis de homogeneidade e textura para a etapa de prensagem. A última etapa de produção dos tijolos foi a prensagem. Feita em uma prensa hidráulica com a aplicação de uma carga uniaxial, esta fase é muito importante porque determina os limites dimensionais da peça, a densidade e a resistência a verde. Neste experimento, adotou-se uma carga de $250 \mathrm{MPa}$, prensando-se $2,5 \mathrm{~kg}$ de mistura por tijolo.

Produziram-se ao todo 4 tijolos, figura 3 , nas dimensões $16 \times 12 \times 6 \mathrm{~cm}^{3}$ que, posteriormente, foram divididos em corpos de prova com as dimensões $16 \times 4 \times$ $4 \mathrm{~cm}^{3}$ para os ensaios de resistência à compressão, massa específica e porosidade.

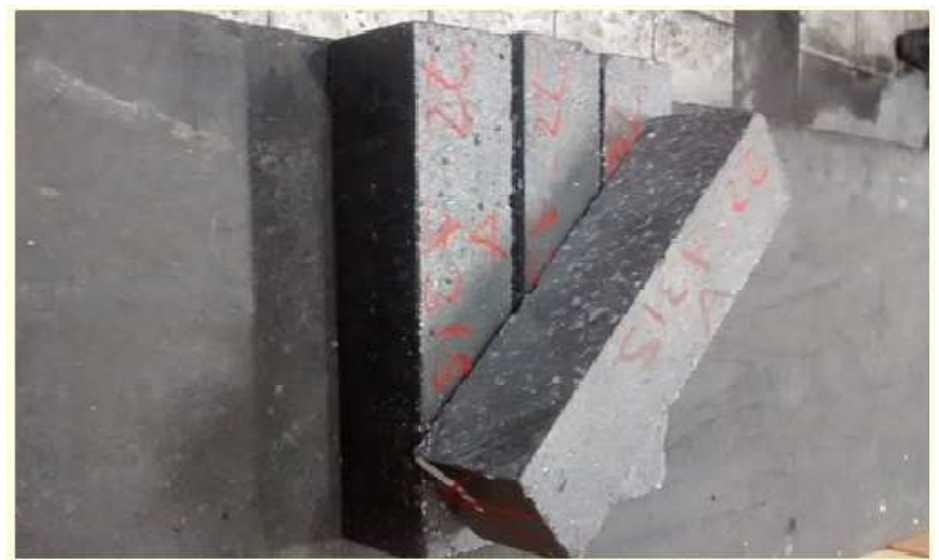

Figura 3 - Tijolos prensados e corpos de prova (CP) para os testes físicos.

\subsection{Porosidade Aparente (Pap)}

Os materiais cerâmicos em geral possuem em sua microestrutura espaços vazios (voids) que são os poros para o Pap. Os poros dividem-se em dois grupos: abertos e fechados, figura 4 . Os poros abertos são aqueles que possuem alguma conexão com a superfície do corpo, ao contrário dos fechados. A porosidade aparente, também referida como propriedade aberta, mede a proporção de poros abertos ou interconectados presentes na estrutura do material. Essa grandeza é importante porque aponta a habilidade do refratário em resistir à penetração de escórias, metais e fluxos em geral. Em adição, materiais mais porosos são isolantes térmicos mais eficientes [11]. 


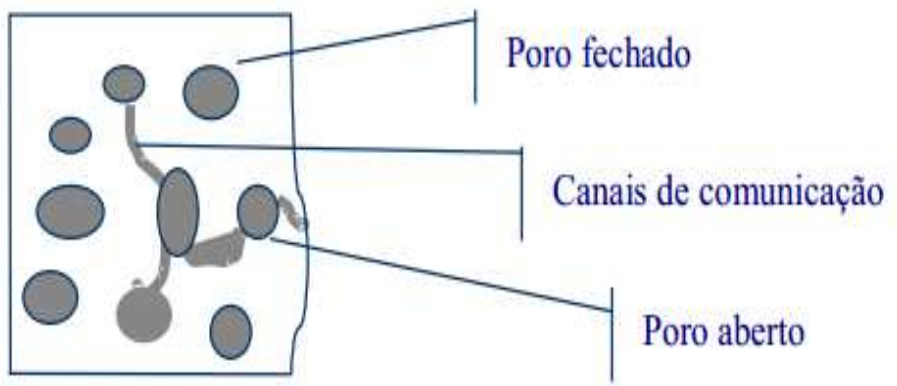

Figura 4. Distribuição de poros abertos e fechados no material refratário [11].

A determinação da Pap foi realizada segundo a norma ABNT NBR 6220 [3] que define seu cálculo pela equação 2 .

Onde:

$$
P_{a p}=\left(\frac{M_{u}-M_{s}}{M_{u}-M_{i}}\right) \times 100
$$

Pap - porosidade aparente;

Mu - massa úmida;

Ms - massa seca;

$\mathrm{Mi}$ - massa imersa.

\subsection{Densidade de Massa Aparente (DMA) e Massa Específica Aparente (MEA)}

A mensuração da densidade de massa aparente foi conduzida de acordo com a norma ABNT NBR 6115:2012 [2]. Essa grandeza é obtida por meio da razão entre a massa do corpo de prova seco e seu volume, conforme equação 3 .

Onde:

$$
\text { DMA }=\frac{\mathrm{m}}{(\mathrm{c})(\mathrm{l})(\mathrm{e})} \times 100
$$

DMA - Densidade de massa aparente $\left(\mathrm{g} / \mathrm{cm}^{3}\right)$;

$\mathrm{m}$ - Massa seca do corpo de prova $(\mathrm{g})$;

c - Comprimento do corpo de prova $(\mathrm{cm})$;

I - Largura do corpo de prova (cm);

e - Espessura do corpo de prova $(\mathrm{cm})$.

O valor de DMA médio encontrado foi de $2,77 \mathrm{~g} / \mathrm{cm}^{3}$. Esse valor é compatível com aqueles encontrados para refratários contendo reciclados de $\mathrm{MgO}-\mathrm{C}$, no entanto é inferior ao de tijolos $\mathrm{MgO}-\mathrm{C}$ com as matérias primas originais (cerca de $3 \mathrm{~g} / \mathrm{cm}^{3}$ ).

A massa específica aparente difere da densidade de massa aparente por incluir em seu cálculo apenas o volume dos poros fechados presentes no refratário. A MEA é determinada pela ABNT NBR 6220 [3] de acordo com a equação 4.

Onde:

$$
\text { MEA }=\left(\frac{M_{s}}{M_{u}-M_{i}}\right) x \rho
$$

MEA - massa específica aparente;

Ms - massa seca;

Mu - massa úmida;

$\mathrm{Mi}$ - massa imersa;

$\rho$ - massa específica do fluído de imersão. 


\subsection{Resistência à Compressão a Temperatura Ambiente (RCTA)}

Conforme Duarte [11], um dos parâmetros mais utilizados na avaliação de refratários é a resistência mecânica. Sua mensuração em altas temperaturas indica a capacidade do material de resistir a cargas mecânicas, além de tensões provocadas por choque térmico e expansão térmica. Já quando determinada à temperatura ambiente, a resistência mecânica não pode prever diretamente o desempenho do refratário, mas aponta a efetividade da ligação ocorrida durante o processo de fabricação.

A RCTA de materiais refratários densos conformados é determinada segundo a norma ABNT MB 71 pela equação 5.

Onde:

$$
\text { RCTA }=\frac{P}{A}
$$

RCTA - resistência à compressão a temperatura ambiente (MPa);

$\mathrm{P}$ - carga de ruptura $(\mathrm{N})$;

A - área de aplicação da carga $\left(\mathrm{m}^{2}\right)$.

\section{RESULTADOS E DISCUSSÃO}

Os testes foram realizados a verde, isto é, sem a queima dos corpos de prova. Isso se deveu a quantidade de amostras disponíveis, que limitariam a queima a uma única temperatura.

\subsection{Porosidade Aparente (Pap)}

Os resultados medidos bem como os parâmetros necessários são apresentados na tabela 6. O método de saturação utilizado foi o de banho-maria e colocação em vácuo de querosene. Utilizou-se querosene em lugar da água em função da resina presente na mistura poder reagir com a água.

Tabela 6 - Resultados das medidas de Porosidade Aparente.

\begin{tabular}{ccccc}
\hline CP & $\begin{array}{c}\text { Massa } \\
\text { seca }\end{array}$ & $\begin{array}{c}\text { Massa } \\
\text { úmida }\end{array}$ & $\begin{array}{c}\text { Massa } \\
\text { imersa }\end{array}$ & PA (\%) \\
\hline 1 & 377,11 & 385,13 & 248,76 & 5,9 \\
2 & 323,33 & 330,45 & 213,95 & 6,1 \\
3 & 368,24 & 376,35 & 243,51 & 6,1 \\
\hline
\end{tabular}

Os valores encontrados são referentes ao refratário sem qualquer cura e, portanto tem tendência a diminuir com o processo de queima dos tijolos, que ocasiona alterações na distribuição e quantidade dos poros pela sinterização dos grãos, conforme Carniglia [7]. No entanto, a porosidade medida é relativamente alta se comparada aos valores geralmente encontrados para refratários $\mathrm{MgO}-\mathrm{C}$ com matérias primas originais, que giram em torno de $3 \%$ em massa.

Os valores de porosidade aparente encontrados podem ter relação com dois fatores: a porosidade inerente aos grãos dos reciclados de $\mathrm{MgO}-\mathrm{C}$ e a menor porção de grafita adicionada no tijolo em estudo. Por ter uma estrutura lamelar, a grafita pode ser deformada plasticamente durante a fabricação dos tijolos, alinhando-se perpendicularmente ao eixo de prensagem sem fraturar, o que confere melhor 
ocupação dos vazios entre os agregados, promovendo menor porosidade e melhor compactação da estrutura obtida [17].

\subsection{Densidade de Massa Aparente (DMA) e Massa Específica Aparente (MEA)}

O valor médio encontrado para a MEA foi de $2,95 \mathrm{~g} / \mathrm{cm}^{3}$. Como esperado, esse valor é superior aquele encontrado para a DMA, ainda assim, é relativamente baixo em relação aos tijolos $\mathrm{MgO}-\mathrm{C}$ sem a presença de reciclados.

\subsection{Resistência à Compressão a Temperatura Ambiente (RCTA)}

Os resultados encontrados no ensaio e os parâmetros utilizados são apresentados na tabela 7 .

\begin{tabular}{ccccc}
\multicolumn{6}{c}{ Tabela 7 - Resultados da determinação da RCTA } \\
\hline CP & $\begin{array}{c}\text { Largura } \\
(\mathrm{mm})\end{array}$ & $\begin{array}{c}\text { Espessura } \\
(\mathrm{mm})\end{array}$ & $\begin{array}{c}\text { Carga } \\
\text { (Kgf) }\end{array}$ & $\begin{array}{c}\text { RCTA } \\
\text { (MPa) }\end{array}$ \\
\hline 1 & 41,09 & 40,77 & 554 & 3,24 \\
2 & 39,95 & 40,78 & 649 & 3,91 \\
3 & 40,99 & 40,75 & 648 & 3,80 \\
\hline
\end{tabular}

A RCTA média encontrada foi de 3,65 MPa. O comportamento da fratura, figura 5, indica que o processo de mistura e prensagem foram adequados, não apresentando anomalias.

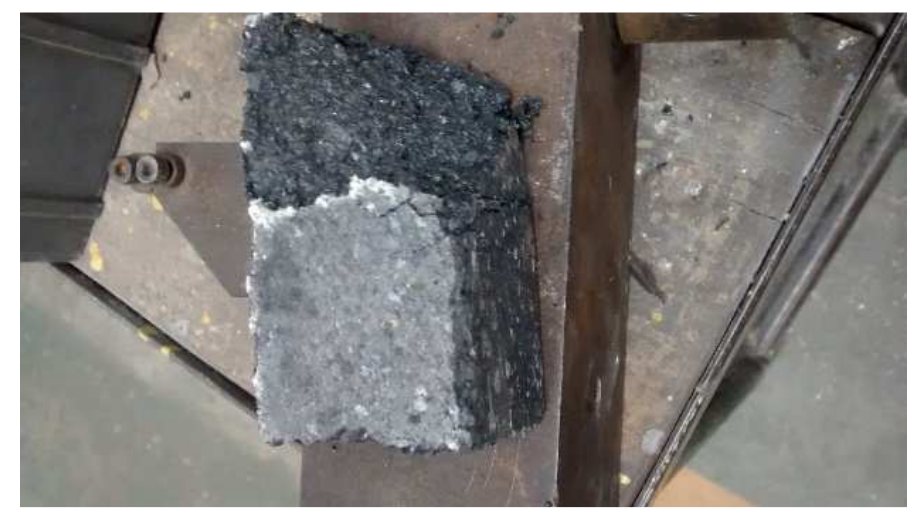

Figura 5 - Corpo de prova após ensaio de compressão.

\section{CONCLUSÃO}

Os resultados obtidos neste trabalho permitem concluir que a substituição total da fonte de magnésia dos refratários conformados de $\mathrm{MgO}-\mathrm{C}$ por resíduos refratários da mesma classe leva à obtenção de propriedades físicas (densidade de massa aparente, massa específica aparente e porosidade aparente) e mecânicas (resistência à compressão a temperatura ambiente) inferiores àquelas encontradas em refratários conformados produzidos a partir da magnésia.

A principal causa da queda nas propriedades estudadas foi o aumento da porosidade total do sistema do tijolo, causado pela ação somatória de dois fatores: a porosidade intrínseca aos grãos de $\mathrm{MgO}-\mathrm{C}$ reciclados e a porosidade criada pelo processo produtivo do tijolo em si. 
Apesar dos resultados apresentados se referirem apenas à condição sem cura e queima, não é esperada uma alteração brusca na porosidade em caso de teste dessas condições, portanto este trabalho aponta para a esperada incapacidade de se produzir tijolos refratários com propriedades aceitáveis contendo majoritariamente composto por reciclados.

\section{Agradecimentos}

Aos professores e orientadores Ricardo Luiz Perez Teixeira, João Bosco dos Santos, Leonardo Neves e Gilberto Lima Fernandes, pela disponibilidade e orientação deste projeto. A Engenheira de Materiais Janaina Santana Orfano pela colaboração e apoio. À Magnesita Refratários S/A, a Usina Siderúrgica Gerdau-Barão de Cocais, MG, a FAPEMIG pelo financiamento a pesquisa e à Faenge-UEMG.

\section{REFERÊNCIAS}

$1 \quad$ NR 25 - Resíduos Industriais. Acesso em: 27 ago. 2014. Disponível em: <http://portal.mte.gov.br/data/files/8A7C816A31B027B80131B4F9B2F25242/nr25.pdf>.

2 Associação Brasileira de Normas Técnicas. NBR 6115: Materiais refratários isolantes conformados - Determinação da densidade de massa aparente. Rio de Janeiro, 2012.

3 Associação Brasileira de Normas Técnicas. NBR 6220: Materiais refratários densos conformados - Determinação da densidade de massa aparente, porosidade aparente, absorção e densidade aparente da parte sólida. Rio de Janeiro, 1997.

4 Associação Brasileira de Normas Técnicas. MB 71: Material refratário denso conformado - Determinação da resistência à compressão a temperatura ambiente: Método de ensaio. Rio de Janeiro, 1991.

5 ASTM C133, Standard Test Methods for Cold Crushing Strength and Modulus of Rupture of Refractories. ASTM-American Society for Testing and Materials, USA, (1993), Book of Standards Volume 15.01, p. 26-31.

6 Magnesita Refratários S/A. Dados de Pesquisa. 2011. Disponível em: <http://www.fdc.org.br/pt/pesquisa/inovacao/cri/minas/Documents/06outubro2011/apres entacao_magnesita.pdf>. Acesso em: 20 out. 2014.

7 Carniglia, Stephen C.; Handbook of Industrial Refractories Technology Principles, Types, Properties and Applications. New Jersey: Noyes Publications,1992.

8 Harbison-Walker Refractories Company. Handbook of Refractory Practice. Pasadena, 2005.

9 Leite, Frederico C. Características e mecanismos de desgaste dos refratários MgO-C usados na linha de escória de panelas de aço. 2013. 185f. Dissertação (Mestrado) Universidade Federal de São Carlos, Programa de Pós-Graduação em Ciência e Engenharia de Materiais.

10 Schacht; Charles A. Refractories Handbook, Ed. CRC Press, 2004.

11 Duarte, Alamar Kassan. Encapsulamento cerâmico de materiais refratários. 2005. 244f. Tese (Doutorado) - Universidade Federal de Minas Gerais, Curso de Pós-Graduação em Engenharia Metalúrgica e de Minas.

12 Lenz e Silva; Guilherme F.B; Refratários para Siderúrgia; In Mourão, Marcelo Breda e Colaboradores. Introdução à siderurgia. Livro técnico da ABM. São Paulo, 2007. Cap. 9, p. 257-307.

13 Sá, R. G. De; Lenz E Silva, Guilherme F. B., Lima, Daniele F. Jr. , Aloyso, Lee, W. E.; Recycling of spent refractories. from metallurgical processing: management and technological approach. In: Congresso bianual da UNITECR, 2007, Dresden/Alemanha.

14 Silva, Rafael Diego Sonaglio da. Avaliação do potencial de reutilização de resíduos refratários em massas refratárias. 2011. Dissertação (Mestrado) - Universidade Federal do Rio Grande do Sul. Escola de Engenharia. Curso de Engenharia 
15 Joardar, Abhijit. MgO-C (Magnesia Carbon) Refractory Bricks: Granulometry. June 14, 2009. Disponível em: < http://viewforyou.blogspot.com.br/2009/06/mgo-c-magnesiacarbon-refractory-bricks.html>. Acesso em: 05 set. 2014.

16 Nascimento Filho, Virgílio F. Técnicas analíticas nucleares de fluorescência de raios X por dispersão de energia (ED-XRF) e por reflexão total (TXRF). 1999. 63f. Universidade de São Paulo, Laboratório de Instrumentação.

17 Luz, Ana Paula da. Concretos refratários avançados com alto teor de carbono. 2010. 243f. Tese (Doutorado) - Universidade Federal de São Carlos, Programa de PósGraduação em Ciência e Engenharia de Materiais. 